\title{
Review
}

Marika L. Forsythe* and Andrew J. Boileau

\section{Use of cannabinoids for the treatment of patients with post-traumatic stress disorder}

https://doi.org/10.1515/jbcpp-2020-0279

Received August 26, 2020; accepted November 18, 2020;

published online March 4, 2021

\section{Abstract}

Objectives: Post-traumatic Stress Disorder (PTSD) is a diagnosis of extreme anxiety caused by a traumatic event. Less than $10 \%$ of individuals who have experienced severe trauma will develop this disorder. Treatment options include various psychotherapies, but not all patients respond to them. Different pharmacological approaches have been explored as potential adjuvants, including using cannabinoids to target the endocannabinoid system to reduce the symptoms and enhance extinction training over the associated fear memories. This review was aimed to determine the effects of using cannabinoids for treatment of PTSD.

Content: For this review, four cohort studies, four randomized clinical trials, one case report, and one case series were obtained from PubMed within the last 10 years. Cannabis extracts, tetrahydrocannabinol (THC) and cannabidiol (CBD), and synthetic cannabinoids were used in the studies to target the cannabinoid receptors 1 and 2. Cannabinoids were shown to improve overall PTSD symptoms, including sleep quality and quantity, hyperarousal, and treatment-resistant nightmares. When participants were undergoing extinction training, cannabinoids given within the same time interval enhanced consolidation and retention.

Summary and Outlook: Cannabinoids have been shown to be an effective treatment option for patients with PTSD. Besides aiding to relieve the symptoms and enhance extinction training, they also are relatively well tolerated. Common adverse effects included light-headedness, forgetfulness, dizziness, and headaches.

\footnotetext{
*Corresponding author: Marika L. Forsythe, Department of Anatomy, Saba University School of Medicine, The Bottom, Saba, Caribbean Netherlands, Phone: +1 (347) 993 1529,

E-mail: m.forsythe@saba.edu. https://orcid.org/0000-0002-96626643

Andrew J. Boileau, Department of Anatomy, Saba University School of Medicine, The Bottom, Saba, Caribbean Netherlands
}

Keywords: cannabidiol; cannabis; dronabinol; fear extinction; nabilone; PTSD.

\section{Introduction}

Post-traumatic stress disorder (PTSD) first became recognized as a diagnosis in the Diagnostic and Statistical Manual of Mental Disorders, Third Edition (DSM-III). An individual with this diagnosis has experienced a traumatic event that invoked extreme emotions, including severe anxiety. Previously, PTSD rates were typically studied in individuals exposed to specific traumatic events (e.g., combat, assault, rape, etc.), but newer studies have since moved to assessing the general population for PTSD [1, 2]. Diagnosis for PTSD must also account for survivors with prolonged, repeat trauma, which has a more complex psychological impact on the individual [3]. The criteria for PTSD have evolved across the DSM editions, with the most recent fifth edition addressing several ambiguities and errors from the previous editions. These include validity of the diagnosis, the trauma symptoms, the role of symptoms in defining its psychopathology, differentiation from other disorders, and various specifiers [4]. However, exposure to a traumatic event does not automatically cause PTSD in an individual. On average, less than $10 \%$ of individuals exposed to a traumatic event will develop the disorder, and $6.8 \%$ will experience it lifelong $[5,6]$.

A significant characteristic of PTSD is an elevated fear response in relation to the traumatic event. Regulation of emotions through fear extinction has been determined to be impaired in the disorder, which leads to the prolonged symptoms. This impairment is acquired due to the traumatic event, as opposed to developing from a predisposing factor. Individuals also have been observed to have an attention bias toward the stimuli, which increases the expression of fear $[7,8]$.

Numerous treatment options have been developed for the disorder, including psychotherapeutic approaches such as exposure therapy, virtual reality therapy, cognitive behavioral therapies and eye movement desensitization and reprocessing. Around $40-70 \%$ of individuals receiving these treatments briefly have noticed significant 
improvement in symptoms and extinction of the learned fear [9]. Not all individuals are ideal candidates for these treatments, however. High rates of suicidality, dissociation, destructive impulsivity, and chaotic life problems are indications that the patients may not respond well to treatment, causing clinicians to become more likely to forgo attempting these therapies. This exposes a need for developing other therapy options [10].

SSRIs have long been considered first-line pharmacological treatment for PTSD; however, only about $60 \%$ of patients respond to it with only $20-30 \%$ reaching full remission [11]. The most promising agents to aid in the process of improving PTSD symptoms were found to target receptors such as the N-methyl-D-aspartic acid (NMDA) receptor [12], the receptors targeted by 3,4-methylenedioxy$\mathrm{N}$-methylamphetamine (MDMA), such as the $5 \mathrm{HT}_{2}$ receptor [13], and the endocannabinoid $\mathrm{CB}_{1}$ receptor $[14,15]$.

Cannabis has been shown to have many clinical uses [16]. It is useful as an analgesic and anti-inflammatory, as well as in relieving associated depression, anxiety, and stress. The two major endogenous cannabinoids are $\mathrm{N}$-arachinodoyl ethanolamine (anandamide, AEA), which acts as a partial agonist [17], and 2-arachidonoyl glycerol (2-AG), which acts as a full agonist $[18,19]$. They bind to the two G-proteincoupled receptors that make up the endocannabinoid system, distributed throughout the brain. This system has been implicated in emotional learning and memory processing, both physiologically and pathologically [20]. The cannabinoid receptor type $1\left(\mathrm{CB}_{1}\right.$ receptor) is involved in modulating various neuronal activities, such as synaptic transmission, while the cannabinoid receptor type $2\left(\mathrm{CB}_{2}\right.$ receptor $)$ is mostly involved with immune response [21, 22].

$\Delta^{9}$-tetrahydrocannabinol (THC) is the principal psychoactive component of cannabis. It acts as a partial agonist at both the $\mathrm{CB}_{1}$ and $\mathrm{CB}_{2}$ receptors, most likely exerting its psychoactive effects through the former [23]. These effects include relaxation, elevated mood, paranoia, perceptual alterations, and cognitive deficits [24]. Stress relief is the primary reason chronic use occurs in cannabis users, regardless of the other adverse effects [25]. Cannabidiol (CBD) can also be extracted from cannabis; however, it does not produce the same psychoactive effects as THC. CBD also interacts with the $\mathrm{CB}$ receptors, but there is growing evidence that suggests it exerts many of its effects via interaction with the $5 \mathrm{HT}_{1 \mathrm{~A}}$ receptor [26].

Two synthetic cannabinoids have been developed for medical uses, both producing similar effects to oral administration of natural cannabis but without the psychoactive properties [27]. Nabilone is a synthetic cannabinoid administered orally and is most similar chemically to $\Delta^{9}$-tetrahydrocannabinol ( $\Delta^{9}$-THC). It is generally prescribed for nausea and vomiting associated with chemotherapy in patients resistant to conventional antiemetic treatments. Dronabinol is another synthetic cannabinoid, also prescribed for nausea and vomiting associated with chemotherapy, as well as anorexia associated with weight loss in patients with Acquired Immune Deficiency Syndrome (AIDS) [28].

The synthetic cannabinoids have been used as treatment for different diseases, including as an anti-emetic, for muscle spasms and pain associated with multiple sclerosis [29], for sleep disorders [30], pain and inflammation [31], and anxiolytic symptoms [32]. They have also been shown to alleviate cannabis withdrawal in users attempting to quit [33]. There are potential risks associated with the drugs, especially when they are abused, such as tachycardia, seizures, and hallucinations [34].

Many $\mathrm{CB}_{1}$ receptors act in brain regions affecting fear memory extinction, such as the amygdala and prefrontal areas. In the amygdala, the release of anandamide has been shown to decrease the activity of its inhibitory interneurons, which allows an increase in activity of output neurons associated with memory extinction [35]. Cannabinoids have also been shown to alter function of the prefrontal cortex, affecting short-term working memory [36]. As such, their role in the extinction is crucial. Studies have shown how $\mathrm{CB}_{1}$-null mice (either with a gene knockout or injection of a $\mathrm{CB}_{1}$ antagonist) failed to adapt to a learned fear response, in contrast to their wild-type counterparts who showed a timedependent reduction in startle response [37].

Using neuroimaging, different brain structures were observed to have hyperactivation or hypoactivation in response to PTSD symptoms. The amygdala has shown hyperresponsivity during these symptoms and a positive correlation linked with the degree of severity [38], and the medial prefrontal cortex has shown hyporesponsiveness during the symptoms and a negative correlation with severity $[39,40]$. Hyperactivations of various brain structures, considered the "limbic" brain, have been observed in other anxiety disorders (e.g., social anxiety disorder and specific phobia disorder), but not hypoactivations. These hypoactivations observed during PTSD symptoms were in regions of the brain associated with the experience or regulation of emotions, further suggesting the involvement of impaired fear extinction [41]. Reduced 2-AG and AEA concentrations have also been observed in PTSD patients, giving more evidence of abnormal $\mathrm{CB}_{1}$ receptor signaling $[42,43]$. Administering synthetic cannabinoids to a healthy individual can cause an increased ventromedial prefrontal cortex and hippocampus activation to a conditioned stimulus previously extinguished during extinction memory recall, indicating its capacity to modulate prefrontal-limbic circuits during fear extinction and consolidation of the 
extinction memory $[44,45]$. However, it is also important to recognize that long-term use of cannabinoids may limit its clinical efficacy, especially if the individual develops a tolerance to the treatment [46].

Numerous studies have used the rat model to test the effects of cannabinoids on extinction training. $\mathrm{CB}_{1}$ receptors in the brain were initially examined in the rat model where antagonization produced an observed impairment of fear extinction retention to a conditioned fear. It was suggested $\mathrm{CB}_{1}$ receptor activation does not supress fear but rather helps to extinguish it and is not involved in its initial acquisition $[37,47]$. Genetic variability in the $\mathrm{CB}_{1}$ receptor has also been shown to play a role in effective fear extinction. The difference in the alleles dictates how robust the observed extinction of fear will be, perhaps helping to explain the underlying differences in anxiety throughout the population [48]. Repeated injection of CBD into the infralimbic cortex has been shown to facilitate fear extinction and prevent reconsolidation of the contextual fear [49]. Using drugs to increase endocannabinoid neurotransmission could prove an effective tool in combination with exposure therapies in treatment of PTSD [50].

\section{Methods}

PubMed was the primary database used to search for articles, with Google Scholar as a secondary database. The following keywords were used for the search: "nabilone", “dronabinol”, “cannabidiol”, “cannabis”, "PTSD”, and "fear extinction". Searches were then limited to human subjects, and studies within the last 10 years (2009-2019). This search yielded 148 articles, without any duplications. Figure 1 depicts how the articles were further discarded and chosen.

The studies chosen were based on one of three analysis methods: (1) Cohort studies of individuals diagnosed with PTSD who were administered a synthetic cannabinoid, (2) Case reports or series with similar methods described above for the cohort studies, or (3) Randomized, placebo-controlled, and double-blinded experimental clinical trials where the test subjects either currently had PTSD or were given a conditioned fear, generally in the form of an electric shock paired with a conditioned stimuli, before being administered the treatment. All reviews, systematic reviews and meta-analyses were excluded. The remaining 110 papers were analyzed for relevance, which greatly reduced the number of eligible papers. Exclusions included: (1) 22 papers that involved patients with PTSD and a co-morbid substance abuse disorder (usually cannabis), (2) 19 papers that examined how PTSD

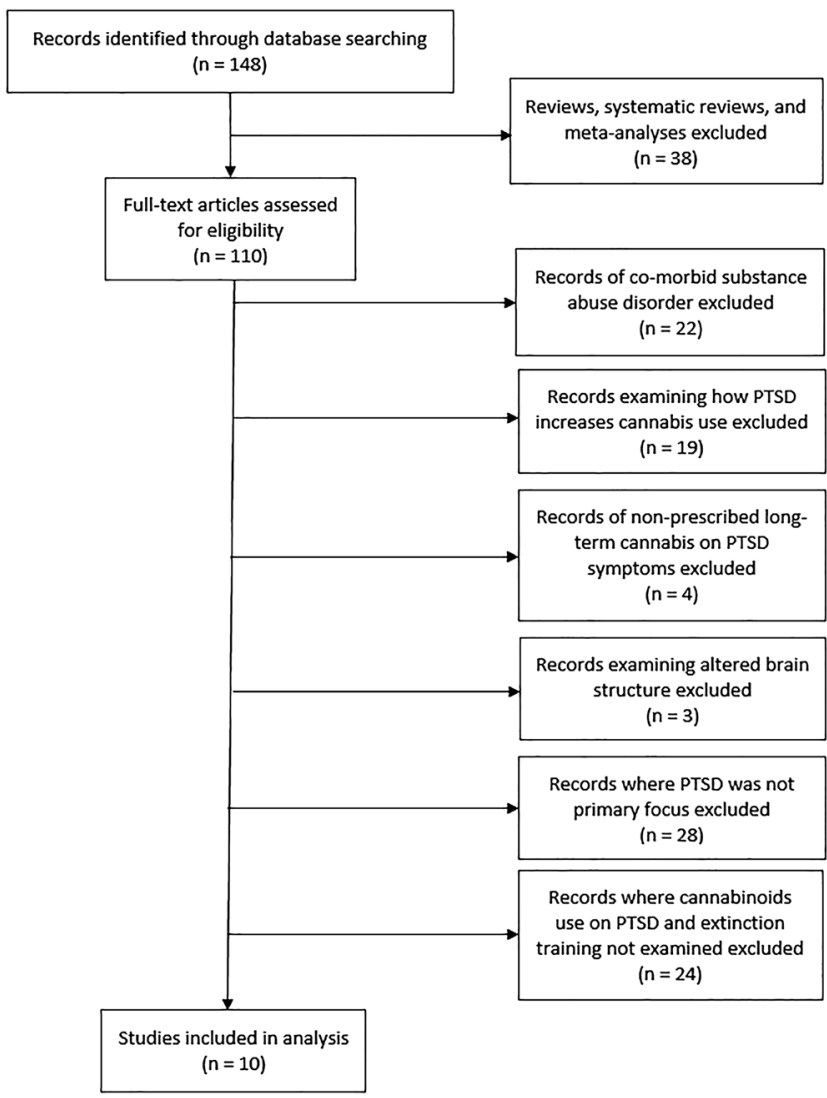

Figure 1: Flowchart showing the discarded and chosen articles.

can increase cannabis use and vice versa, (3) four papers that investigated the effects of non-prescribed (uncontrolled) long-term cannabis use on PTSD symptoms, (4) three papers that looked at the changes experienced from cannabis on brain structures instead of PTSD symptoms or extinction training, (5) 28 papers where the primary focus was not on the PTSD experienced by the patients, and (6) 24 papers where the use of cannabinoids on PTSD symptoms and extinction training was not examined. These exclusions yielded 10 studies: four cohort studies, four randomized clinical trials, one case report, and one case series.

\section{Results}

Results are summarized in Table 1.

\section{Cannabis extracts (THC or CBD)}

Six studies used cannabis or cannabis-extract treatments and observed the effect on PTSD-like symptoms. Greer et al. [51] examined the PTSD symptoms of 80 patients being 
Table 1: Summary of the reviewed studies.

\begin{tabular}{|c|c|c|c|c|c|}
\hline First author & $\begin{array}{l}\text { Date of } \\
\text { publication }\end{array}$ & Study design & Study population & Therapy or exposure & Outcomes/Results \\
\hline ireer, G. R. & $\begin{array}{l}\text { January-March } \\
2014\end{array}$ & $\begin{array}{l}\text { Retrospective } \\
\text { cohort study }\end{array}$ & $\begin{array}{l}\text { Patients diagnosed } \\
\text { with PTSD }\end{array}$ & $\begin{array}{l}\text { Treatment with } \\
\text { medical cannabis }\end{array}$ & $\begin{array}{l}\text { Many of the patients experienced a reduction } \\
\text { in their PTSD symptoms with cannabis use }\end{array}$ \\
\hline Rabinak, C. A. & January 2013 & $\begin{array}{l}\text { Randomized } \\
\text { controlled } \\
\text { trial }\end{array}$ & $\begin{array}{l}\text { Healthy adult human } \\
\text { volunteers }\end{array}$ & $\begin{array}{l}\text { Treatment with oral } \\
\text { dronabinol, a syn- } \\
\text { thetic THC }\end{array}$ & $\begin{array}{l}\text { The patients who received THC showed a lower } \\
\text { skin conductance response when exposed to } \\
\text { the previously extinguished conditioned } \\
\text { stimuli during testing of extinction memory } \\
\text { recall, suggesting the recovery of fear had } \\
\text { been prevented }\end{array}$ \\
\hline Klumpers, F. & April 2012 & $\begin{array}{l}\text { Randomized } \\
\text { controlled } \\
\text { trial }\end{array}$ & $\begin{array}{l}\text { Healthy adult human } \\
\text { volunteers }\end{array}$ & $\begin{array}{l}\text { Treatment with syn- } \\
\text { thetic } \Delta^{9} \text {-THC, } \\
\text { D-cycloserine }\end{array}$ & $\begin{array}{l}\text { The patients who received THC observed a } \\
\text { significant reduced skin conductance } \\
\text { response during extinction training, however } \\
\text { the effect was not retained during the two day } \\
\text { retention test suggesting a dependence on } \\
\text { the acute effects of the drug }\end{array}$ \\
\hline Das, R. K. & January 2013 & $\begin{array}{l}\text { Randomized } \\
\text { controlled } \\
\text { trial }\end{array}$ & $\begin{array}{l}\text { Healthy adult human } \\
\text { volunteers }\end{array}$ & $\begin{array}{l}\text { Treatment with CBD } \\
\text { administered prior to } \\
\text { extinction of a } \\
\text { learned fear or } \\
\text { post-extinction }\end{array}$ & $\begin{array}{l}\text { The patients who received CBD administered } \\
\text { post-extinction showed evidence of extinction } \\
\text { learning consolidation }\end{array}$ \\
\hline Shannon, S. & October 2016 & Case report & $\begin{array}{l}\text { Child diagnosed with } \\
\text { PTSD }\end{array}$ & $\begin{array}{l}\text { Treatment with CBD } \\
\text { supplements and } \\
\text { sublingual spray }\end{array}$ & $\begin{array}{l}\text { The patient experienced an increase in sleep } \\
\text { quality and quantity and a decrease in anxiety }\end{array}$ \\
\hline Elms, L. & April 2019 & Case series & $\begin{array}{l}\text { Patients diagnosed } \\
\text { with PTSD }\end{array}$ & $\begin{array}{l}\text { Treatment with oral } \\
\text { CBD }\end{array}$ & $\begin{array}{l}\text { Many patients who received CBD experienced } \\
\text { a decrease in PTSD symptoms, including } \\
\text { improved sleep, focus, and mood, and } \\
\text { decreased anxiety }\end{array}$ \\
\hline Roitman, $\mathrm{P}$. & August 2014 & $\begin{array}{l}\text { Prospective } \\
\text { cohort study }\end{array}$ & $\begin{array}{l}\text { Patients diagnosed } \\
\text { with PTSD }\end{array}$ & $\begin{array}{l}\text { Treatment with oral } \\
\Delta^{9}-\text { THC as an add-on } \\
\text { therapy to their cur- } \\
\text { rent PTSD } \\
\text { medications }\end{array}$ & $\begin{array}{l}\text { The patients who received the } \Delta^{9} \text {-THC add-on } \\
\text { therapy experienced a decrease in PTSD } \\
\text { symptom severity, including hyperarousal, } \\
\text { sleep quality, and frequency of nightmares }\end{array}$ \\
\hline Jetly, R. & January 2015 & $\begin{array}{l}\text { Randomized, } \\
\text { double-blind, } \\
\text { placebo- } \\
\text { controlled } \\
\text { cross } \\
\text { over design } \\
\text { study }\end{array}$ & $\begin{array}{l}\text { Patients diagnosed } \\
\text { with PTSD }\end{array}$ & $\begin{array}{l}\text { Treatment with nabi- } \\
\text { lone, a synthetic } \\
\text { cannabinoid }\end{array}$ & $\begin{array}{l}\text { Many patients who received nabilone showed } \\
\text { improvement in PTSD symptoms, including a } \\
\text { reduction in distressing dreams }\end{array}$ \\
\hline Fraser, G. A. & February 2009 & $\begin{array}{l}\text { Prospective } \\
\text { cohort } \\
\text { study }\end{array}$ & $\begin{array}{l}\text { Patients diagnosed } \\
\text { with PTSD }\end{array}$ & $\begin{array}{l}\text { Treatment with nabi- } \\
\text { lone, a synthetic } \\
\text { cannabinoid }\end{array}$ & $\begin{array}{l}\text { Many patients who received nabilone experi- } \\
\text { enced a cessation of nightmares or a signifi- } \\
\text { cant reduction in nightmare intensity }\end{array}$ \\
\hline Cameron, C. & October 2014 & $\begin{array}{l}\text { Retrospective } \\
\text { cohort } \\
\text { study }\end{array}$ & $\begin{array}{l}\text { Patients with severe } \\
\text { mental illness }\end{array}$ & $\begin{array}{l}\text { Treatment with nabi- } \\
\text { lone, a synthetic } \\
\text { cannabinoid }\end{array}$ & $\begin{array}{l}\text { Many patients who received nabilone showed } \\
\text { improvement in PTSD symptoms, including } \\
\text { hours slept, frequency of nightmares, and } \\
\text { chronic pain }\end{array}$ \\
\hline
\end{tabular}

PTSD, Post-traumatic Stress Disorder; CBD, Cannabidiol; THC, Tetrahydrocannabinol.

evaluated for the New Mexico Medical Cannabis program before (in a retrospective chart review) and after they entered the program through a cohort study. The Clinician Administered Posttraumatic Scale for DSM-IV (CAPS) scores were used to evaluate the symptoms. The evaluations were conducted between mid-2008 to late 2011, with the first scores of the patients being obtained before initiating cannabis use and the second scores being obtained after enrolling in the program and initiating cannabis use. The data was analyzed using a two-way ANOVA to determine any significance [51].

A significant decrease $(\mathrm{p}<0.0001)$ in CAPS scores was observed from before and after cannabis use, from $98.8 \pm 17.6$ (mean \pm SD) to $22.5 \pm 16.9$, indicating a reduction in overall PTSD symptoms. Even when CAPS scores were examined for 
individual Criteria groups (B: re-experiencing, C: numbing and avoidance, D: hyperarousal), a significant reduction was observed $(\mathrm{p}<0.0001)$ in each. Criterion B decreased from $29.5 \pm 6.4$ to $7.3 \pm 5.9$, Criterion $C$ from $38.2 \pm 8.4$ to $8.7 \pm 8.0$, and Criterion D, from $31.0 \pm 6.2$ to $6.6 \pm 6.0$. Criterion A relates to the presence of traumatic events and immediate emotional response to them, and thus a change in score could not be obtained [51].

In the next study, Rabinak et al. [52] conducted a randomized, double-blinded, placebo-controlled clinical trial. The study recruited 29 healthy volunteers, 12 males and 17 females aged 21-45. Thirteen participants had a minimal history of marijuana use as defined by the authors, while none had a history of neurological, psychiatric or medical illness. The females also participated in the study when their estrogen levels were low. On day 1 of the study, subjects underwent partial discrimination fear conditioning involving two neutral visual stimuli and bursts of noise. Participants were presented with one of the two stimuli on a computer screen, followed by an aversive white noise burst through headphones $(\mathrm{CS}+\mathrm{U})$. The conditioning consisted of 15 non-reinforced presentations of the stimuli mixed with eight presentations of the stimuli followed by noise. A third stimuli was also presented, but never paired with the noise (CS-). Skin conductance response (SCR) was measured by attaching carbon fiber electrodes between the first and second phalanges of the second and third digits of the left hand. It was during the subsequent extinction training on day 2 where the conditioned response to one of the stimuli was extinguished $(C S+E)$. Then, the participants were randomly assigned to receive a capsule with $7.5 \mathrm{mg}$ of THC (the lowest effective dose that produces behavioral and subjective effects) or a placebo capsule containing only dextrose. The extinction training involved 15 presentations of CS + E and 15 presentations of CS-. Day 3 assessed extinction retention through 20 non-reinforced presentation of all the stimuli ( $\mathrm{CS}+\mathrm{E}, \mathrm{CS}+\mathrm{U}$, and CS-), and during presentation of each stimuli the participants indicated whether they would hear an associated noise burst [52].

There was no difference between the two groups in terms of fear acquisition, or early extinction learning, but those in the THC group exhibited a lower increase in SCR score when exposed to the stimulus during extinction recall (late extinction learning $0.13 \pm 0.05$, mean \pm SEM, vs. extinction recall test $0.22 \pm 0.08$ ) in comparison to the placebo group (late extinction learning $0.13 \pm 0.04$ vs. extinction recall test $0.37 \pm 0.11$ ). While there was no significant increase observed in the THC group ( $\mathrm{p}=0.37$ ), there was a significant difference in the placebo group $(\mathrm{p}<0.05)$, indicating THC had likely helped keep the extinguished fear from returning upon reexposure to the stimuli [52].
Klumpers et al. [53] obtained similar results in their study, where 54 healthy volunteers were recruited for a randomized, double-blinded, placebo-controlled clinical trial and were given either synthetic $\Delta^{9}$-THC, D-cycloserine (DCS, a partial NMDA receptor agonist), or a placebo (unspecified). There were 31 females and 23 males aged 18-30, separated into 18 participants per group. Over the course of the study, two participants dropped out due to adverse effects of the THC, one was removed after testing positive for cannabis, and the EMG data of four participants was unusable due to equipment failure, bringing the study total down to 47 participants. Exclusion criteria included never having been exposed to marijuana, no current drug use, low startle reactivity, not pregnant, and no first or second-degree family members with a history of psychosis. Participants all underwent a form of fear conditioning on day 1, where participants were presented with two neutral faces, colored either blue or yellow. During the four fear conditioning trials, participants received a small shock on their wrist (CS+). The other four trials did not have an associated shock (CS-). On day 2, participants were given either $10.0 \mathrm{mg}$ of $\Delta^{9}$-THC, $250.0 \mathrm{mg}$ DCS or placebo. Extinction training commenced $2 \mathrm{~h}$ post-ingestion, consisting of two blocks of four CS+ and four CS- trials without shock reinforcement. Retention phases 1 and 2 occurred on day 4, which included two blocks without shock reinforcement. After the first retention phase, participants were also presented with a black screen and a fixation cross for $35 \mathrm{~s}$ and received three un-signaled shocks spaced $5 \mathrm{~s}$ apart to assess differential impact on retention between the substances. Startle response was measured with EMG from the orbicularis oculi muscle under the right eye, and SCR was measured by attaching two electrodes on the palm of the left hand [53].

When examining fear-potentiated startle across the study, there was no significant difference observed in any of the treatment groups (all $F$-values $<1.5$, n.s.). There was no observed difference in extinction between the DCS and placebo groups $(F(1,34)=0.7$, n.s.), but significantly reduced SCR was observed between the THC and placebo groups during extinction training $(F(1,34)=6.0, \mathrm{p}=0.02)$. However, the effect was not retained during the two day retention test, suggesting dependence on the acute effects of the drug. The authors did not report means or errors for each group [53].

Das et al. [54] recruited 48 participants for a randomized, double-blinded, placebo-controlled clinical trial. The participants were aged 18-35 with no history of serious mental or physical health problems, substance misuse, learning impairments, or neurological history, normal or corrected-to-normal color vision, and not pregnant. They were assigned to one of three groups, 16 participants each, and were given $32.0 \mathrm{mg}$ of CBD either prior to extinction to a 
learned fear, post extinction to the learned fear or a placebo containing ethanol at either time. When the first group received CBD prior to extinction, the other two groups received the placebo. Likewise, when the second group received $\mathrm{CBD}$ post extinction, the other two groups received the placebo. The conditioned fear was learned on day 1 , where participants were presented with either a red or yellow box on a computer screen in "Room A". One of the stimuli would be paired with an electric shock $50 \%$ of the time (CS+), and the other stimuli would not (CS-). There were 16 trials of each. Participants then underwent extinction training in "Room B" on the computer screen, where they were presented with the same stimuli as previously but with no associated shock. On day 2, they participated in the recall and reinstatement phases. In the recall phase, the stimuli were presented in the fear conditioning and extinction training contexts, except in an alternating fashion. The reinstatement phase presented the stimuli in the same manner, but prior to these trials the participants were presented with a shock in each context without an associated stimulus. Participants were told before these last two phases that they would be seeing the same stimuli in the same rooms, increasing the reliance on memory of the conditioning and extinction sessions. SCR was also measured throughout the study [54].

Results for recall indicated a main effect of group ( $F$ $\left.[2,40]=2.991, \mathrm{p}=0.062, \eta_{\mathrm{p}}{ }^{2}=0.13\right)$, which aligns with the lower post correction ratings observed when CBD was administered post-extinction $(\mathrm{p}=0.047)$. This indicates a consolidation of extinction learning. However, no difference was observed between CBD pre-extinction and placebo administrations. Significantly greater SCRs to the $\mathrm{CS}+$ than the CS- in conditioning context were also observed, indicating a higher shock expectancy $(t[37]$ $=2.796, p=0.008$ ). SCRs also exhibited a trend in the reinstatement phase for a group and context interaction $(F$ $\left.[2,35]=2.836, \mathrm{p}=0.073, \eta_{\mathrm{p}}{ }^{2}=0.147\right)$, reflecting how CBD administered either pre- or post-extinction resulted in a trend level of reduction in reinstatement of autonomic contextual responding ( $p=0.045)$; however, this effect did not reach significance post-correction [54].

In the fifth study, Shannon [55] analyzed the case report of a ten-year-old girl who was diagnosed with PTSD secondary to sexual abuse at the age of three, and neglect. Her symptoms included anxiety, insomnia, outburst at school, suicidal ideation, and self-destructive ideations. The patient was prescribed a variety of medications and supplements to reduce her symptoms, including melatonin, clonidine, imipramine, inositol, magnesium, and diphenhydramine. While these offered some relief, the patient did not respond to the treatments long-term [55].
Three years after the initial evaluation, the patient was started on a trial of CBD oil. CBD supplements of $25.0 \mathrm{mg}$ were given at bedtime, and 6.0-12.0 mg of CBD sublingual spray was administered during the day as needed for anxiety. Gradually over five months the patient experienced an increase in sleep, both in quality and quantity, and a decrease in anxiety. This was measured by administering the Sleep Disturbance Scale for Children and the Screen for Anxiety Related Disorders (SCARED) over the five months, where each score was observed to fall for the patient. A score of more than 50 on the Sleep scale is indicative of a sleep disorder, and a SCARED score over 25 is indicative of a highly probable anxiety disorder [56, 57]. The patient experienced a Sleep scale score decrease from 59 to 38 , and a SCARED score decrease from 34 to 18 [55].

Elms et al. [58] is a retrospective case series that examined the effect of oral CBD on the symptoms of PTSD in 11 adult patients who were receiving treatment at an outpatient psychiatric clinic. Inclusion criteria for the series included a cut-off score of 33 on the PTSD Checklist for the DSM-5 (PCL-5) and at minimum two follow-up appointments after the initial appointment, decreasing the original 21 patients down to these 11. Presence of another psychiatric comorbidity, aside from an active thought disorder, did not exclude the patient from the study. Four of the patients received CBD as an oral capsule (22.0-28.0 mg), one received it in an oral liquid spray (about $1.5 \mathrm{mg}$ ), and six received both forms either concurrently or sequentially throughout the study. They were instructed to take CBD once or twice a day, depending on severity of symptoms, which equated to a median oral capsular dose of $25.0 \mathrm{mg}$ and a median liquid dose of $9.0 \mathrm{mg}$ per day. The dose was adjusted at each four week appointment based on effectiveness. The mean total dose of CBD at the conclusion of the study period at eight weeks was $48.64 \mathrm{mg}$. The PCL-5 assessment was completed by the patients every four weeks to monitor for changes to their PTSD symptoms. Side effects and tolerability were assessed and analyzed through patient selfreporting, as well as any comments or complaints [58].

The mean PCL-5 score obtained at the initial appointments was $51.82 \pm 9.13$ (mean $\pm \mathrm{SD}$ ). After the first four weeks of treatment 10 of the participants reported a decrease in PTSD symptoms, with the mean score dropping to $40.73 \pm 12.92$. After another four weeks of treatment eight of the participants reported a further decrease in symptoms, lowering the mean score to $37.14 \pm 14.38$. The remaining three patients had worsening symptoms, resulting in a mean score increase of $8.0 \pm 6.08$. However, despite this increase experienced by some of the patients, 10 of the patients still reported PCL- 5 scores lower than at the initial appointment. Four of the patients continued to receive CBD 
for 36 weeks or more, who experienced a mean PCL-5 score drop from $57.75 \pm 6.20$ to $29.25 \pm 9.88$. A possible effect of CBD was also observed on nightmares, which was indicated in question 2 on the PCL-5 questionnaire. Of the eight patients who responded to this question with a severity rating of three or higher, four reported fewer nightmares over the course of the study. Of the original 21 patients before applying the inclusion criteria, eight reported an improvement in the quality of sleep, three had decreased anxiety, one experienced improved focus, and one had an improved mood [58].

\section{Add-on therapy}

Roitman et al. [59] looked at use of oral $\Delta^{9}$-THC as an add-on therapy for patients with chronic PTSD. Ten patients with chronic PTSD currently receiving treatment, typically four or more medications including clonazepam, were selected for this cohort study, and started at $2.5 \mathrm{mg}$ THC drops twice a day. After two days, if the treatment was well tolerated the dose was increased to $5.0 \mathrm{mg}$ THC drops twice a day for three weeks. Patients went through a baseline assessment before initiating treatments, and then weekly assessments until completion of the study. All parameters in the study were measured with surveys. There were three females and seven males, with a mean age of 52.3 years (SD 8.3). Exclusion criteria included frequent dissociated episodes, women who were currently pregnant or nursing or not using a reliable method of contraception, participants with suicidal ideation, and those with concurrent psychosis, alcohol, drug abuse, or prior cannabis use within the last six months [59].

Although there were a few mild adverse effects (e.g., dry mouth, headaches, or dizziness), all the patients tolerated the add-on therapy well. There were also significant decreases in severity of many of the PTSD symptoms, including Clinical Global Impression-Severity Scale (CGI-S; $6.0 \pm 0.47$, mean \pm SD, to $4.9 \pm 0.99, \mathrm{p}<0.02)$, Clinical Global Impression-Improvement Scale (CGI-I; $3.5 \pm 0.52$ to $2.7 \pm 1.25$, $\mathrm{p}<0.03$ ), hyperarousal ( $32.3 \pm 4.73$ to $24.3 \pm 9.11$, $\mathrm{p}<0.02)$, sleep quality $(17.20 \pm 2.65$ to $13.9 \pm 4.48, \mathrm{p}<0.05)$, frequency of nightmares $(0.81 \pm 0.55$ to $0.44 \pm 0.41, \mathrm{p}<0.04)$ and total NES scores ( $32.2 \pm 11.29$ to $22.9 \pm 8.7, \mathrm{p}<0.002)$. Two of the participants even attained complete elimination of nightmares by the end of the study [59].

\section{Nabilone}

Three studies examined the efficacy of the synthetic cannabinoid, nabilone, in treatment of PTSD symptoms. Jetly et al.
[60] studied 10 participants with PTSD in a randomized, double-blinded, placebo-controlled clinical crossover trial. Exclusion criteria included significant cognitive impairment, serious medical conditions, or a positive screen for illicit substances. Participants were divided equally into two groups, receiving either nabilone or a placebo (unspecified), over a seven week period and the effects on PTSD-associated nightmares were observed. The treatment groups were then switched for another seven week period. Over each period, the initial dose of $0.5 \mathrm{mg}$ was increased by $0.5 \mathrm{mg}$ weekly to a maximum of $3.0 \mathrm{mg}$. One subject was unable to participate in the second period [60].

The results showed improvement in $70 \%$ of participants at the end of the nabilone treatment period, compared to $22.2 \%$ at the end of the placebo treatment period. Also, $44 \%$ at the end of the nabilone treatment period reported no distressing dreams during the last week. Efficacy was measured by the mean reduction in the CAPS Recurring and Distressing Scores, Frequency + Intensity, which showed to be significant (nabilone: $-3.6 \pm 2.4$, mean \pm SD, vs. placebo: $-1.0 \pm 2.1, p=0.03$ ). Significant improvement was also observed in the nabilone groups in the Clinical Global Impression of Change (nabilone: $1.9 \pm 1.1$ vs. placebo: $3.2 \pm 1.2, p=0.05)$ and the General Well Being Questionnaire reports (nabilone: increase from $28.4 \pm 21.6$ to $49.3 \pm 21.6$ vs. placebo: decrease from $29.0 \pm 20.8$ to $23.0 \pm 17.2, \mathrm{p}=0.04$ ) [60].

Fraser [15] tested nabilone for treatment-resistant nightmares in PTSD patients. This cohort study recruited 47 patients ( 27 females and 20 males) with an age range from 26 to 68 . Inclusion criteria required the participants have a minimum current nightmare frequency of once weekly. They were initially given $0.5 \mathrm{mg}$ of nabilone daily, which was increased or decreased to achieve optimal dose. The observed effective dose ranged from 0.2 to $4.0 \mathrm{mg}$. The patients were then seen weekly to monitor effects until either a satisfactory response was achieved, or treatment was terminated due to adverse effects (including lightheadedness, forgetfulness, dizziness, and headaches). This study did not report any statistics or errors [15].

Before beginning the study, patients were given a tracking sheet to record hours of sleep and the intensity of their nightmares, with a scale from 1 to 5 (with five being the most intense). Throughout the study 34 patients experienced total cessation or a decrease in severity of nightmares, with 28 patients having total cessation of nightmares and six having satisfactory reduction. However, only four patients were able to successfully discontinue treatment following 4-12 months of the therapy without the nightmares returning. The other patients typically had reoccurrence of nightmares within the first two nights. Other benefits observed in some of the cases 
included improvement in sleep time, reduction of daytime flashbacks, and elimination of night sweats [15].

In the third study, Cameron et al. [61] examined the effects of nabilone on various PTSD symptoms, including insomnia, nightmares, and the management of chronic pain. This cohort study recruited 104 male inmates, aged 19-55, with severe mental illness. A retrospective chart review was used to observe the effects of nabilone. All participants had been prescribed nabilone after their admission. Among the mental illnesses observed, 95.2\% of the participants had been diagnosed with an anxiety disorder, $95.2 \%$ with either an alcohol or substance use disorder, $67.3 \%$ with a mood disorder, and $12.5 \%$ with a psychotic disorder. The range for nabilone treatment among the participants was between one day to 36 weeks (mean length 11.2 weeks), with initial dose ranging between 0.5 and $2.0 \mathrm{mg}$ (mean $1.4 \mathrm{mg}$ ) and final dose ranging $0.5-6.0 \mathrm{mg}$ (mean $4.0 \mathrm{mg}$ ). Those who took nabilone for longer than 20 weeks experienced a higher mean final dose $(4.6 \mathrm{mg})$ in comparison to those who took it for 8-12 weeks (3.6 mg) [61].

All pre-treatment and post-treatment measures exhibited a significant improvement. Hours slept increased from $5.0 \pm 1.4($ mean $\pm S D)$ to $7.2 \pm 0.2(\mathrm{p}<0.001)$, number of nights with nightmares per week decreased from $5.2 \pm 2.2$ to $0.9 \pm 1.8(\mathrm{p}<0.001)$, and $89.6 \%$ of the participants reported improvement in their chronic pain. Improvements in sleep time, quality, and nightmares were typically seen within the first 1-2 weeks of treatment and were maintained for the entirety of the study. The Posttraumatic Checklist-Civilian score (PCL-C) also decreased significantly, from $54.7 \pm 13.0$ to $38.8 \pm 7.1$ ( $\mathrm{p}=0.001)$, which matched a change of moderate PTSD symptoms to borderline mild. The Global Assessment of Function (GAF) also increased significantly, from $45.0 \pm 6.9$ to $58.2 \pm 8.4$ ( $\mathrm{p}=0.001)$, which matched a change of serious to moderate impairment in functioning [61].

\section{Discussion}

Cannabinoids have been shown to improve various PTSD symptoms, including decreasing treatment-resistant nightmares, hyperarousal, daytime flashbacks, increasing sleep quality and general well being $[15,51,58,60,61]$. It is also usually well-tolerated, with minimal adverse effects including light-headedness, forgetfulness, dizziness, and headaches. However, some patients occasionally experience symptoms causing them to discontinue treatment, although this is not a common occurrence $[15,59]$.

When used in conjunction with extinction training, cannabinoids increase the effectiveness in eliminating the fear memories and preventing their reoccurrences [52-54].
The consolidation of extinction learning was particularly effective when the cannabinoids were given post-extinction training, as opposed to prior to it. A potential reason for this is consolidation of extinction learning likely occurs primarily after completion of the training. Therefore, there would be a higher amount of cannabinoids present to aid in this process if they are administered after the training instead of before. Evidence to this possibility is seen in Das et al. [54] and Klumpers et al. [53]. In the former, the most effective extinction occurred in the treatment group who received their CBD post-extinction training. Then in the latter, participants were given the CBD treatments $2 \mathrm{~h}$ before beginning the extinction training. During the two-day retention test the effects from the training did not remain, which could be due to a lower amount of cannabinoids being present at the time of optimal consolidation. Rabinak et al. [52] did not specify when the participants received the $\mathrm{CBD}$ treatments relative to the extinction training. However, based on the results observed in the other studies it can hypothesized that the treatment was administered either during or after extinction training, as the results of this study showed how CBD could help retain the fear memory extinction.

A common, and expected, limitation of these studies is small sample size. The studies requiring participants to have chronic PTSD would have the most difficulties with recruitment, primarily due to the exclusion criteria. For example, Roitman et al. [59] and Jetly et al. [60] required their participants not have a substance use disorder (SUD); however, roughly $40 \%$ of individuals with PTSD are found to have co-occurring SUD [62]. This exclusion is important in these studies as individuals with both PTSD and SUD have a poorer treatment outcome and require more treatment sessions [63, 64]. Jetly et al. [60] did attempt to mitigate this by using a cross-over study design, but still suffered from a relatively small sample size.

Weaknesses in the testing methods were observed in some of the studies. Cameron et al. [61] described a dosing schedule for the 104 participants, which ranged from one day to 36 weeks depending on how well the treatment was tolerated. It was not described later how the researchers accounted for this large variation in treatment length, as a participant who took nabilone for nine months longer than another patient would likely experience different results. However, this is never addressed; the results only indicate how many of the participants experienced the same effects. Additionally, many of the participants experienced comorbidities to their PTSD, including SUD, mood disorders and psychotic disorders. As mentioned previously, treating PTSD when another co-occurring disorder is present can affect overall treatment outcomes. Due to the variety in disorders among the participants and likely concurrent 
treatments, it is difficult to accurately compare the results. Finally, Greer et al. [51], Roitman et al. [59], Jetly et al. [60], Fraser [15], Shannon [55], Cameron et al. [61], and Elms et al. [58] all examined the effects of cannabinoids on PTSD symptoms. Changes in symptoms were reported by most participants, and while certain symptoms could be reported objectively (i.e., frequency of nightmares) others involve subjective interpretations. For instance, the participants' definition for "good quality of sleep" may differ from one another. Reliability and validity are two criteria that can be used to assess the adequacy of a scale and aid in quantifying subjective data [65].

While Shannon [55] reported similar results observed in the previous studies, case reports come with their own weaknesses. For instance, there is only one participant being followed. This creates a significant sampling size bias. This limits the validity of the results as they have not been reproduced more than once. The patient in this study was also on other supplements when she started the CBD treatments. There is no way to tell if any of the other medications altered the effects of the CBD, which then brings the validity of the results into question. While the child appeared to greatly benefit from the CBD, she would need to be followed for longer while only taking the CBD treatment to fully understand its effects and benefits.

Similar weaknesses are also found in Elms et al. [58], where not only is the sample size small but the patients were also being treated for other psychiatric comorbidities when initiating the CBD treatments. These other medications included antidepressants, anticonvulsants, antipsychotics, anxiolytics, and beta-blockers. Some patients also used cannabis daily, although were not considered to have an SUD. As in the Shannon [55] case report, it is impossible to determine whether these therapies influenced the effect of the CBD, which casts doubt on the overall findings. The method for receiving the CBD varied among the patients as well, without a precise dosing system. Without a definitive guideline for administration, it limits the ability to determine what amount of CBD produces optimal effects on PTSD symptoms.

The randomized clinical trials were designed properly to obtain the most accurate results. Rabinak et al. [52], Klumpers et al. [53], Das et al. [54], and Jetly et al. [60] all used randomized, double-blind, placebo-controlled study designs, making them the "gold standard" of epidemiology studies [66]. They help prevent many biases during the study, including selection bias, reporting bias, and observer bias. There are certain biases that are difficult to avoid with this type of study, however. These include non-compliance, withdrawals after randomization, attrition/losses to followup, ineligible patients enrolled and misclassification of outcome [67]. Self-selection bias is another concern for all types of studies involving PTSD. This is due to the participants having the opportunity to evaluate the conditions of the study before committing. This occurs when the researcher is obtaining informed consent, which gives the participant the option to decline [68].

\section{Future considerations}

More clinical trials on humans are required to increase our understanding of the endocannabinoid system and its role in PTSD, as well as how cannabinoids can affect symptoms and the extinction training process. Further exploration will also allow development of more effective pharmacological treatments, with the ability to treat the symptoms while diminishing the adverse effects causing patient discontinuation. For instance, a potential target for novel psychotherapy development related to cannabinoids is the fatty acid amide hydrolase (FAAH) enzyme. It is important in endocannabinoid metabolism, playing a role in the levels of circulating 2-AG and AEA $[69,70]$. It is hypothesized that FAAH inhibitors would be an effective treatment option for individuals with PTSD by increasing the amount of the endogenous endocannabinoid to normal levels and suppressing the hyperactivity observed in the amygdala. This could minimize the PTSD symptoms experienced by the individual, and it should have no effect on memory consolidation of conditioned fears [71, 72].

\section{Summary and outlook}

The presented studies reveal promising evidence in favor of cannabinoids as a treatment option for individuals with PTSD. CBD and THC have been shown to be effective treatments for PTSD symptoms overall, as well as enhancing consolidation of extinction training used to eliminate conditioned fear. Nabilone, a synthetic cannabinoid developed for medicinal purposes, has shown to provide the same benefits as the cannabis extracts but with fewer adverse effects. By treating the fear memories and aiding with their extinction, it can be possible to treat the PTSD symptoms at the source of the cause.

Acknowledgments: We thank the members of the RLRA committee of Saba University School of Medicine for helpful comments and direction.

Research funding: None declared. 
Author contributions: All authors have accepted responsibility for the entire content of this manuscript and approved its submission.

Competing interests: Authors state no conflict of interest.

\section{References}

1. Hidalgo RB, Davidson JR. Posttraumatic stress disorder: epidemiology and health-related considerations. J Clin Psychiatr 2000;61(7 Suppl):5-13.

2. Galea S, Nandi A, Vlahov D. The epidemiology of post-traumatic stress disorder after disasters. Epidemiol Rev 2005;27:78-91.

3. Herman JL. Complex PTSD: a syndrome in survivors of prolonged and repeated trauma. J Trauma Stress 1992;5:377-91.

4. North CS, Suris AM, Smith RP, King RV. The evolution of PTSD criteria across editions of DSM. Ann Clin Psychiatr 2016;28: 197-208.

5. Breslau N. The epidemiology of trauma, PTSD, and other posttrauma disorders. Trauma Violence Abuse 2009;10:198-210.

6. Kessler RC, Berglund P, Demler O, Jin R, Merikangas KR, Walters EE. Lifetime prevalence and age-of-onset distributions of DSM-IV disorders in the National Comorbidity Survey Replication. Arch Gen Psychiatr 2005;62:593-602.

7. Milad MR, Pitman RK, Ellis CB, Gold AL, Shin LM, Lasko NB, et al. Neurobiological basis of failure to recall extinction memory in posttraumatic stress disorder. Biol Psychiatr 2009;66:1075-82.

8. Fani N, Tone EB, Phifer J, Norrholm SD, Bradley B, Ressler KJ, et al. Attention bias towards threat is associated with exaggerated fear expression and impaired extinction in PTSD. Psychol Med 2012; 42:533-43.

9. Bradley R, Greene J, Russ E, Dutra L, Westen D. A multidimensional meta-analysis of psychotherapy for PTSD. Am J Psychiatr 2005;162:214-27.

10. Becker CB, Zayfert C. Integrating DBT-based techniques and concepts to facilitate exposure treatments for PTSD. Cognit Behav Pract 2001;8:108-22.

11. Ipser JC, Stein DJ. Evidence-based pharmacology of posttraumatic stress disorder (PTSD). Neuropsychopharmacology 2012;15:465-73.

12. Kishimoto A, Kanekao M, Gotoha Y, Hashimoto K. Ifenprodil for the treatment of flashbacks in female posttraumatic stress disorder patients with a history of childhood sexual abuse. Biol Psychiatr 2012;71:e7-8.

13. Mithoefer MC, Wagner MT, Mithoefer AT, Jerome L, Doblin R. The safety and efficacy of \pm 3 ,4-methylenedioxymethamphetamineassisted psychotherapy in subjects with chronic, treatmentresistant posttraumatic stress disorder: the first randomized controlled pilot study. J Psychopharmacol 2011;25:439-52.

14. De Oliveira AL, Pasqualini GB, DiehI F, Molina VA, Quillfeldt JA. Opposite action of hippocampal $\mathrm{CB}_{1}$ receptors in memory reconsolidation and extinction. Neuroscience 2008;154: 1648-55.

15. Fraser GA. The use of a synthetic cannabinoid in the management of treatment-resistant nightmares in posttraumatic stress disorder (PTSD). CNS Neurosci Ther 2009;15:84-8.

16. Bridgeman MB, Abazia DT. Medical Cannabis: history, pharmacology, and implications for the acute care settling. P T 2017;42:180-8.
17. Pertwee RG. Receptors and channels targeted by synthetic cannabinoid receptor agonists and antagonists. Curr Med Chem 2010;17:1360-81.

18. Gonsiorek W, Lunn C, Fan X, Narula S, Lundell D, Hipkin RW. Endocannabinoid 2-arachidonyl glycerol is a full agonist through human type 2 cannabinoid receptor: antagonism by anandamide. Mol Pharmacol 2000;57:1045-50.

19. Savinainen JR, Järvinen T, Laine K, Laitinen JT. Despite substantial degradation, 2-arachidonoylglycerol is a potent full efficacy agonist mediating $\mathrm{CB}(1)$ receptor-dependent $\mathrm{G}$-protein activation in rat cerebellar membranes. Br J Pharmacol 2001;134:664-72.

20. Drumond A, Madeira N, Fonseca R. Endocannabinoid signaling and memory dynamics: a synaptic perspective. Neurobiol Learn Mem 2017;138:62-77.

21. Chevaleyre V, Takahashi KA, Castillo PE. Endocannabinoidmediated synaptic plasticity in the CNS. Annu Rev Neurosci 2006; 29:37-76.

22. Klein TW. Cannabinoid-based drugs as anti-inflammatory therapeutics. Nat Rev Immunol 2005;5:400-11.

23. Pertwee RG. The diverse CB1 and CB2 receptor pharmacology of three plant cannabinoids: delta9-tetrahydrocannabinol, cannabidiol and delta9-tetrahydrocannabivarin. Br J Pharmacol 2008;153:199-215.

24. D'Souza DC, Perry E, MacDougall L, Ammerman Y, Cooper T, Wu YT, et al. The psychotomimetic effects of intravenous delta9-tetrahydrocannabinol in healthy individuals: implications for psychosis. Neuropsychopharmacology 2004;29:1558-72.

25. Hyman SM, Sinha R. Stress-related factors in cannabis use and misuse: implications for prevention and treatment. J Subst Abuse Treat 2009;36:400-13.

26. Gomes FV, Reis DG, Alves FH, Corrêa FM, Guimarães FS, Resstel LB. Cannabidiol injected into the bed nucleus of the stria terminalis reduces the expression of contextual fear conditioning via $5-\mathrm{HT} 1 \mathrm{~A}$ receptors. J Psychopharmacol 2012;26:104-13.

27. Badowski ME. A review of oral cannabinoids and medical marijuana for the treatment of chemotherapy-induced nausea and vomiting: a focus on pharmacokinetic variability and pharmacodynamics. Canc Chemother Pharmacol 2017;80:441-9.

28. Kramer JL. Medical marijuana for cancer. CA A Cancer J Clin 2015; 65:109-22.

29. Rog DJ, Nurmiko TJ, Friede T, Young CA. Randomized, controlled trial of cannabis-based medicine in central pain in multiple sclerosis. Neurology 2005;65:812-9.

30. Ramar K, Rosen IM, Kirsch DB, Chervin RD, Carden KA, Aurora RN. Medical cannabis and the treatment of obstructive sleep apnea: an American academy of sleep medicine position statement. J Clin Sleep Med 2018;14:679-81.

31. Di Marzo V. Inhibitors of endocannabinoid breakdown for pain: not so FA(AH)cile, after all. Pain 2012;153:1785-6.

32. Blessing EM, Steenkamp MM, Manzanares J, Marmar CR. Cannabidiol as a potential treatment for anxiety disorders. Neurotherapeutics 2015;12:825-36.

33. Gunderson EW, Haughey HM, Ait-Daoud N, Joshi AS, Hart CL. "Spice" and "K2" Herbal Highs: a case series and systematic review of the clinical effects and biopsychosocial implications of synthetic cannabinoid use in humans. Am J Addict 2012;21:320-6.

34. Harris CR, Brown A. Synthetic cannabinoid intoxication: a case series and review. J Emerg Med 2013;44:360-6.

35. Azad SC, Monory K, Marsicano G, Cravatt BF, Lutz B, Zieglgänsberger W, et al. Circuitry for associative plasticity in the 
amygdala involves endocannabinoid signaling. J Neurosci 2004; 24:9953-61.

36. Lafourcade M, Elezgarai I, Mato S, Bakiri Y, Grandes P, Manzoni OJ. Molecular components and functions of the endocannabinoid system in mouse prefrontal cortex. PloS One 2007;2:e709.

37. Kamprath K, Marsicano G, Tang J, Monory K, Bisogno T, Di Marzo V, et al. Cannabinoid CB1 receptor mediates fear extinction via habituation-like processes. J Neurosci 2006;26: 6677-86.

38. Protopopescu X, Pan H, Tuescher O, Cloitre M, Goldstein M, Engelien W, et al. Differential time courses and specificity of amygdala activity in posttraumatic stress disorder subjects and normal control subjects. Biol Psychiatr 2005;57:464-73.

39. Williams LM, Kemp AH, Felmingham K, Barton M, Olivieri G, Peduto A, et al. Trauma modulates amygdala and medial prefrontal responses to consciously attended fear. Neuroimage 2006;29:347-57.

40. Rougemont-Bücking A, Linnman C, Zeffiro TA, Zeidan MA, LebronMilad K, Rodriguez-Romaguera J, et al. Altered processing of contextual information during fear extinction in PTSD: an fMRI study. CNS Neurosci Ther 2011;17:227-36.

41. Etkin A, Wager TD. Functional neuroimaging of anxiety: a metaanalysis of emotional processing in PTSD, social anxiety disorder, and specific phobia. Am J Psychiatr 2007;164: 1476-88.

42. Neumeister A, Normandin MD, Pietrzak RH, Piomelli D, Zheng $M-Q$, Gujarro-Anton A, et al. Elevated brain cannabinoid $C B 1$ receptor availability in posttraumatic stress disorder: a positron emission tomography study. Mol Psychiatr 2013;18:1034-40.

43. Hill MN, Bierer LM, Makotkine I, Golier JA, Galea S, McEwen BS, et al. Reductions in circulating endocannabinoid levels in individuals with post-traumatic stress disorder following exposure to the World Trade Center attacks. Psychoneuroendocrinology 2013;38:2952-61.

44. Rabinak CA, Angstadt M, Lyons M, Mori S, Milad MR, Liberzon I, et al. Cannabinoid modulation of prefrontal-limbic activation during dear extinction learning and recall in humans. Neurobiol Learn Mem 2014;113:125-34.

45. Rabinak CA, Peers C, Marusak HA, Ghosh S, Phan KL. Effects of acute $\Delta^{9}$-tetrahydrocannabinol on next-day extinction recall is mediated by post-extinction resting-state brain dynamics. Neuropharmacology 2018;143:289-98.

46. Lin H-C, Mao S-C, Chen P-S, Gean P-W. Chronic cannabinoid administration in vivo compromises extinction of fear memory. Learn Mem 2008;15:876-84.

47. Pickens CL, Theberge FR. Blockade of CB1 receptors prevents retention of extinction but does not increase low pre-incubated conditioned fear in the fear incubation procedure. Behav Pharmacol 2014;25:23-31.

48. Heitland I, Klumpers F, Oosting RS, Evers DJJ, Kenemans JL, Baas JMP. Failure to extinguish fear and genetic variability in human cannabinoid receptor 1. Transl Psychiatry 2012;2:e162.

49. Do Monte FH, Souza RR, Bitencourt RM, Kroon JA, Takahashi RN. Infusion of cannabidiol into infralimbic cortex facilitates fear extinction via $\mathrm{CB}_{1}$ receptors. Behav Brain Res 2013;250:23-7.

50. Morena M, Berardi A, Colucci P, Palmery M, Trezza V, Hill MN, et al. Enhancing endocannabinoid neurotransmission augments the efficacy of extinction training and ameliorates traumatic stress-induced behavioral alterations in rats. Neuropsychopharmacology 2018;43:1284-96.
51. Greer GR, Grob CS, Halberstadt AL. PTSD symptom reports of patients evaluated for the New Mexico Medical Cannabis program. J Psychoact Drugs 2014;46:73-7.

52. Rabinak CA, Angstadt M, Sripada CS, Abelson JL, Liberzon I, Milad MR, et al. Cannabinoid facilitation of fear extinction memory recall in humans. Neuropharmacology 2013;64:396-402.

53. Klumpers F, Denys D, Kenemans JL, Grillon C, van der Aart J, Baas JMP. Testing the effects of $\Delta^{9}$-THC and D-cycloserine on extinction of conditioned fear in humans. J Psychopharmacol 2012;26:471-8.

54. Das RK, Kamboj SK, Ramadas M, Yogan K, Gupta V, Redman E, et al. Cannabidiol enhances consolidation of explicit fear extinction in humans. Psychopharmacology 2013;226:781-92.

55. Shannon S. Effectiveness of cannabidiol oil for pediatric anxiety and insomnia as part of posttraumatic stress disorder: a case report. Perm J 2016;20:108-11.

56. Ferreira VR, Carvalho LB, Ruotolo F, de Morais JF, Prado LB, Prado GF. Sleep disturbance scale for children: translation, cultural adaptation, and validation. Sleep Med 2009;10: 457-63.

57. Birmaher B, Khetarpal S, Cully M, Brent D, McKenzie S. Screen for child anxiety related disorders (SCARED). Pittsburgh, PA: Western Psychiatric Institute and Clinic, University of Pittsburgh; 1995.

58. Elms L, Shannon S, Hughes S, Lewis N. Cannabidiol in the treatment of post-traumatic stress disorder: a case series. J Alternative Compl Med 2019;25:392-7.

59. Roitman P, Mechoulam R, Cooper-Kazaz R, Shalev A. Preliminary, open-label, pilot study of add-on oral $\Delta^{9}$-tetrahydrocannabinol in chronic post-traumatic stress disorder. Clin Drug Invest 2014;34: 587-91.

60. Jetly R, Heber A, Fraser G, Boisvert D. The efficacy of nabilone, a synthetic cannabinoid, in the treatment of PTSD-associated nightmares: a preliminary randomized, double-blind, placebocontrolled cross-over design study. Psychoneuroendocrinology 2015;51:585-5.

61. Cameron C, Watson D, Robinson J. Use of a synthetic cannabinoid in a correlation population for posttraumatic stress disorder-related insomnia and nightmares, chronic pain, harm reduction, and other indications. J Clin Psychopharmacol 2014; 34:559-64.

62. Petrakis IL, Rosenheck R, Desai R. Substance use comorbidity among veterans with posttraumatic stress disorder and other psychiatric illness. Am J Addict 2011;20:185-9.

63. Kaier E, Possemato K, Lantinga LJ, Maisto SA, Ouimette PC. Associations between PTSD and healthcare utilization among $\mathrm{OEF} / \mathrm{OIF}$ veterans with hazardous alcohol use. Traumatology 2014;20:142.

64. Bowe A, Rosenheck R. PTSD and substance use disorder among veterans: characteristics, service utilization and pharmacotherapy. J Dual Diagn 2015;11:22-32.

65. Elasy TA, Gaddy G. Measuring subjective outcomes: rethinking reliability and validity. J Gen Intern Med 1998;13:757-61.

66. Hulley SB, Cummings SR, Browner WS, Grady DG, Newman TB. Designing clinical research, 3 rd ed. Philadelphia: Lippincott Williams and Wilkins, A Walters Kluwer Business; 2007:251-65 pp.

67. Misra S. Randomized double blind placebo control studies, the "Gold Standard" in intervention based studies. Indian J Sex Transm Dis 2012;33:131-4. 
68. Woodward SH, Stegman WK, Pavao JR, Arsenault NJ, Hartl TL, Drescher KD, et al. Self-selection bias in sleep and psychophysiological studies of posttraumatic stress disorder. J Trauma Stress 2007;20:619-23.

69. Petrosino S, Di Marzo V. FAAH and MAGL inhibitors: therapeutic opportunities from regulating endocannabinoid levels. Curr Opin Invest Drugs 2010;11:51-62.

70. Gunduz-Cinar O, Hill MN, McEwen BS, Holmes A. Amygdala FAAH and anandamide: mediating protection and recovery from stress. Trends Pharmacol Sci 2013;34:637-44.
71. Gunduz-Cinar O, MacPherson KP, Cinar R, Gamble-George J, Sugden K, Williams B, et al. Convergent translational evidence of a role for anandamide in amygdala-mediated fear extinction, threat processing and stress-reactivity. Mol Psychiatr 2013b;18: 813-23.

72. Boileau I, Westwood D, Richardson D, Rhind S, Tyndale RF, Lanius $R$, et al. 51. Investigating endocannabinoid mechanisms in posttraumatic stress disorder: neuroimaging studies with the novel fatty acid amide hydrolase probe, [11C]CURB. Biol Psychiatr 2018;83:S21. 